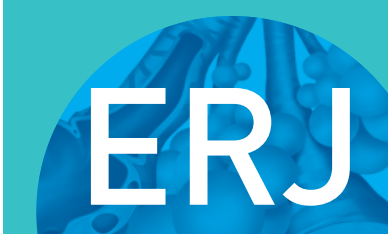

open research
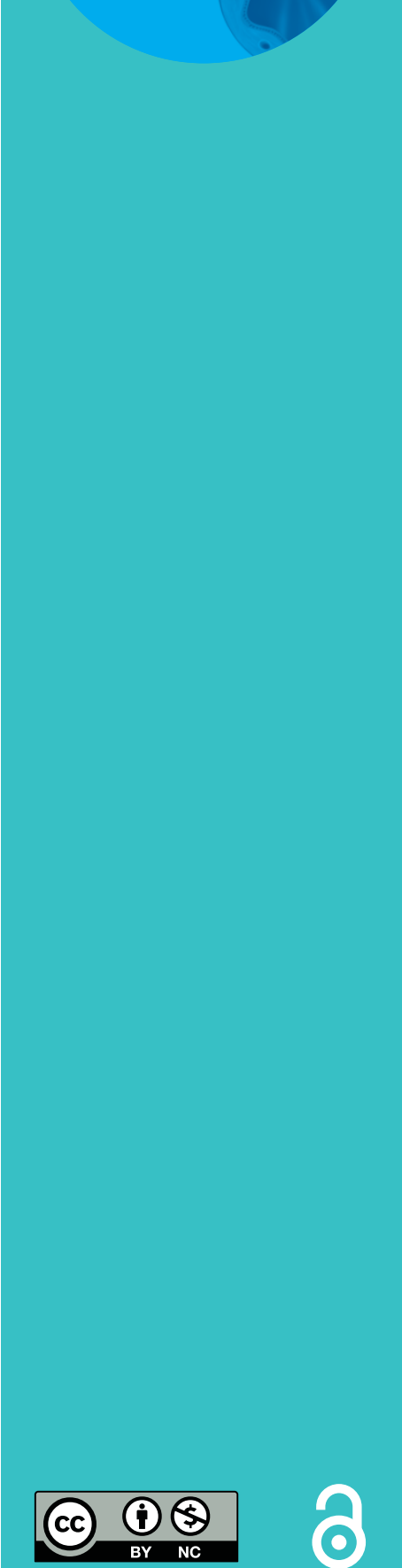

\section{Lung function changes over 8 years and testosterone markers in both sexes: UK Biobank}

\author{
Alexandra Lenoir (10 ${ }^{1,2}$, Elaine Fuertes ${ }^{1}$, Francisco Gómez-Real ${ }^{3,4}$, \\ Benedicte Leynaert ${ }^{5}$, Diana A. van der Plaat ${ }^{1}$ and Debbie Jarvis ${ }^{1,6}$
}

Affiliations: ${ }^{1}$ National Heart and Lung Institute, Imperial College London, London, UK. ${ }^{2}$ Centre Hospitalier Universitaire Vaudois, Lausanne, Switzerland. ${ }^{3}$ Dept of Clinical Science, University of Bergen, Bergen, Norway. ${ }^{4}$ Dept of Gynecology and Obstetrics, Haukeland University Hospital, Bergen, Norway. ${ }^{5}$ Université Paris-Saclay, UVSQ, Univ. Paris-Sud, Inserm, Équipe d'Épidémiologie respiratoire intégrative, CESP, Villejuif, France. ${ }^{6}$ MRC-PHE Centre for Environment and Health, Imperial College London, London, UK.

Correspondence: Alexandra Lenoir, Office BH06-188, Centre Hospitalier Universitaire Vaudois, Rue du Bugnon 46, 1011 Lausanne, Switzerland. E-mail: alexandra.lenoirdachuv.ch

ABSTRACT Higher levels of testosterone have been associated with better lung function in crosssectional population-based studies. The role of testosterone in lung function in women and in lung function decline in men or women is unclear.

We studied 5114 men and 5467 women in the UK Biobank with high-quality spirometry at baseline (2006-2010) and 8.4 years later. We studied cross-sectional associations of total testosterone (TT), calculated free testosterone (cFT), free androgen index (FAI) and sex hormone-binding globulin (SHBG) with forced expiratory volume in $1 \mathrm{~s}\left(\mathrm{FEV}_{1}\right)$, forced vital capacity $(\mathrm{FVC})$ and $\mathrm{FEV}_{1} / \mathrm{FVC}$ using linear regression and associations of baseline markers with lung function decline using linear mixed-effects regression.

Men with higher levels of TT had higher $\mathrm{FEV}_{1}(27.56 \mathrm{~mL}$ per interquartile range increase TT, 95\% CI 5.43-49.68) and FVC (48.06 mL, 95\% CI 22.07-74.06) at baseline. Higher cFT levels were associated with higher $\mathrm{FEV}_{1}$ and FVC among physically active men only. In women, higher FAI and cFT levels were associated with lower lung function at baseline and higher levels of TT, cFT and FAI were associated with slightly attenuated $\mathrm{FEV}_{1}$ and FVC decline. Higher levels of SHBG were associated with better lung function in both sexes but slightly accelerated decline in men.

In this population-based sample, higher levels of TT were associated with better lung function in men and higher levels of cFT with better lung function in physically active men. A small attenuation of lung function decline with higher levels of TT, cFT and FAI was seen in women only.

@ERSpublications

Higher levels of testosterone are associated with better lung function in men, especially if physically active, but not in women. A small attenuation of lung function decline with higher testosterone levels is seen in women only. https://bit.ly/382d0xT

Cite this article as: Lenoir A, Fuertes E, Gómez-Real F, et al. Lung function changes over 8 years and testosterone markers in both sexes: UK Biobank. ERJ Open Res 2020; 6: 00070-2020 [https:// doi.org/10.1183/23120541.00070-2020].

This article has supplementary material available from openres.ersjournals.com

Received: 14 Feb 2020 | Accepted after revision: 23 June 2020

Copyright $\odot$ ERS 2020. This article is open access and distributed under the terms of the Creative Commons Attribution Non-Commercial Licence 4.0. 


\section{Introduction}

Low total testosterone (TT) levels have been associated with worse lung function in population-based cross-sectional studies and are common in men with COPD [1]. Small randomised controlled trials of testosterone supplementation, lasting up to 6 months, in the setting of rehabilitation programmes, showed improvements in lean body mass, strength and quality of life in male COPD patients [2-4] but not when supplementation occurred outside of a dedicated training programme $[5,6]$. No study showed improvement in exercise capacity or pulmonary function [4-6], and the evidence for prescribing testosterone replacement therapy (TRT) in COPD patients is insufficient [1].

While some studies have shown a role of androgens in the regulation of lung maturation $[7,8]$, their role in lung function later in life is poorly understood [9]. No longitudinal study on the association between androgen levels and lung function decline in either sex exists and no study of this association in women, although there are important differences in androgen levels between sexes related to ageing [10]. In men, circulating testosterone levels gradually decrease as of 35 to 40 years [11]. In women, circulating concentrations of total and bioavailable testosterone are approximately 20-times lower than in men [12] and decline with age before menopause [13], altering little through the menopausal transition [14, 15].

We examined sex-specific associations of total and bioavailable testosterone levels with spirometric lung function and its decline over 8 years in participants from a large population-based adult cohort (UK Biobank). As a secondary aim, we studied the change in testosterone levels over 4 years and its association with lung function at the end of this period in a subset of participants.

\section{Methods}

\section{Study population}

UK Biobank is a multicentre, population-based, prospective cohort that recruited approximately 500000 adults aged 40 to 69 years throughout the UK between 2006 and $2010\left(\mathrm{~T}_{0}\right)$. Two follow-ups have taken place: 2012-2013 $\left(\mathrm{T}_{1}\right)$ and 2014-ongoing $\left(\mathrm{T}_{2}\right)$. The UK Biobank received ethical approval from the UK Research Ethics Committee North West-Haydock. Additional details are provided in the supplementary material.

For our main analyses, we included men and women who took part in the baseline assessment and second follow-up until March 2019 and who 1) provided high-quality spirometry on both occasions and 2) had

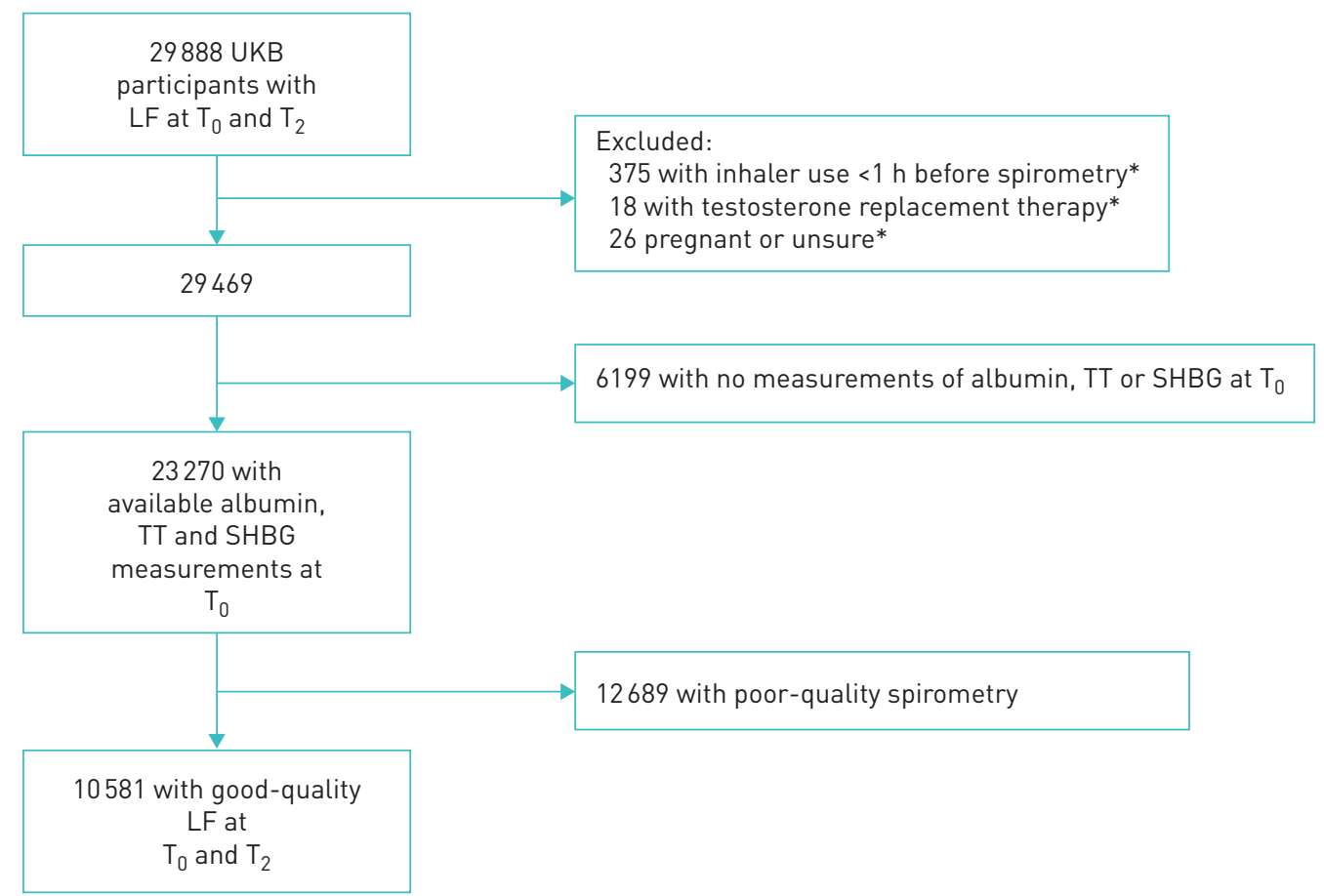

FIGURE 1 Flow chart of $\mathrm{T}_{0}-\mathrm{T}_{2}$ participants included for main analysis, with acceptable and reproducible spirometry at baseline $\left(T_{0}, 2006-2010\right)$ and second follow-up $\left(T_{2}, 2014-2019\right)$ as well as available measurements for TT, SHBG and albumin at $T_{0}$. LF: lung function; SHBG: sex hormone-binding globulin; TT: total testosterone; UKB: UK Biobank. *: at any time point. 
available measures of sex hormone-binding globulin (SHBG), total testosterone (TT) and albumin at baseline. We excluded participants who used an inhaler less than $1 \mathrm{~h}$ prior to spirometry, participants using testosterone replacement and women who were (or thought they may be) pregnant (figure 1).

\section{Lung function measurements}

Trained nurses or healthcare technicians performed spirometry using a standard protocol and a Vitalograph Pneumotrac 6800 spirometer (Vitalograph, Buckingham, UK). We used high-quality spirometry, defined as at least one acceptable and reproducible blow during one test session. A blow was deemed acceptable if the back extrapolated volume was $<5 \%$ of forced vital capacity (FVC) or $0.15 \mathrm{~L}$, whichever greater; time to peak flow was not excessive; an adequate plateau ( $1 \mathrm{~s}$ volume plateau) existed at the end of the test; no cough was detected during the manoeuvre; and the expiration lasted more than $6 \mathrm{~s}$; or the test was explicitly accepted by the investigator. In keeping with the European Respiratory Society (ERS)/American Thoracic Society (ATS) quality criteria [16], only reproducible measures were included (highest acceptable measure and any other measure within $150 \mathrm{~mL}$, or within $100 \mathrm{~mL}$ if FVC is $\leqslant 1$ litre). However, due to time constraints, each participant was only allowed three attempts to provide two acceptable blows instead of the recommended maximum of eight attempts.

Participants did not perform spirometry if they reported a chest infection in the last month; history of detached retina; heart attack or surgery to eyes, chest or abdomen in the last 3 months; history of a collapsed lung; pregnancy; currently on medication for tuberculosis.

\section{Biomarker measurements}

Blood samples taken at $\mathrm{T}_{0}$ and from the subsample at $\mathrm{T}_{1}$ were tested for SHBG and TT using a chemiluminescent immunoassay (Beckman Coulter Ltd., UK, analytical platform DXI 800), by two-step sandwich and competitive-binding method, respectively, with results expressed in $\mathrm{nmol} \cdot \mathrm{L}^{-1}$. Albumin levels were obtained through colorimetric measures (Beckman Coulter Ltd., UK, analytical platform AU5800) and results expressed in $\mathrm{g} \cdot \mathrm{L}^{-1}$.

We included SHBG in our analysis as it is the main carrier protein for testosterone [17] and appears relevant for health (e.g. low SHBG levels have been associated with the metabolic syndrome and type 2 diabetes [18]). As most testosterone is bound to either SHBG or albumin (therefore biologically unavailable) we used recognised methods to calculate circulating free testosterone (cFT) and free androgen index (FAI) as proxies for bioavailable testosterone. Vermeulen's formula adapted by Ho [19] was used to calculate $\mathrm{cFT}=\left(\mathrm{TT}-\mathrm{N}-\mathrm{SHBG}+\sqrt{ }\left((\mathrm{N}+\mathrm{SHBG}-\mathrm{TT})^{2}+4 \times \mathrm{N} \times \mathrm{TT}\right)\right) / 2 \times \mathrm{N}$, where $\mathrm{N}=0.5217 \times$ albumin. FAI was calculated as $\mathrm{FAI}=(\mathrm{TT} / \mathrm{SHBG}) \times 100$.

\section{Statistical analysis}

Simple linear regression was used to examine cross-sectional associations of baseline TT, SHBG, FAI and cFT with baseline forced expiratory volume in $1 \mathrm{~s}\left(\mathrm{FEV}_{1}\right), \mathrm{FVC}$ and $\mathrm{FEV}_{1} / \mathrm{FVC}$ ratio. Associations of hormonal biomarkers with decline in $\mathrm{FEV}_{1}, \mathrm{FVC}$ and $\mathrm{FEV}_{1} / \mathrm{FVC}$ ratio over an 8-year period were assessed using linear mixed-effects regression with random intercepts.

All analyses were stratified by sex. We adjusted both models for age, age ${ }^{2}$, standing height, body mass index (continuous), smoking status (never/former/current), pack-years, area level measure of deprivation (Townsend score [20]), number of days per week of moderate physical activity ( $>10 \mathrm{~min}$ ), fresh fruit intake $(0-1$ portion, $2-3$ portions, $\geqslant 4$ portions) and time of day of appointment (before 12:00 versus 12:00 and later) to control for diurnal variability of hormone levels. For the associations with lung function at baseline, all covariates were entered as the value provided at baseline. For the associations with lung function decline, age and age ${ }^{2}$ were entered as the values provided at baseline while all other covariates were entered as time-varying.

As some studies showed beneficial effects of testosterone replacement on lean body mass and strength, we examined effect modification by physical activity (exact question provided in supplementary material). The interaction term was composed of a categorical variable for moderate physical activity ( $\leqslant 3$ days $\cdot$ week $^{-1}$ and $\geqslant 4$ days.week ${ }^{-1}$ ) and the sex-specific IQR increase of the hormonal marker.

To address our secondary aim, simple linear regression was used to study the association of lung function at first follow-up with hormonal change between baseline and follow-up. Models were adjusted for the same covariates as above plus lung function and hormonal levels at baseline to account for differences in these values at baseline and difference in the time of day of blood sampling between baseline and follow-up appointments (both in the morning, both in the afternoon or one before and one after midday).

Effect estimates are reported per sex-specific interquartile range (IQR) of each hormonal measure. 
Linearity was verified through generalised additive models.

All analyses were conducted using STATA 15.0 (StataCorp, College Station, TX, USA).

\section{Results}

Overall, 29888 individuals had lung function measurements at $\mathrm{T}_{0}$ and at $\mathrm{T}_{2}$ by March 2019 (figure 1). Mean time between the two visits was 8.3 years. After applying the exclusion criteria, 10581 had baseline measurements for TT, SHBG and albumin available and reproducible and acceptable quality spirometry on both occasions. Their main characteristics are in table 1, compared to subjects who did not provide acceptable spirometry on both occasions.

In both sexes, participants with high-quality spirometry at both time points were more likely to have smoked, live in less-deprived areas and have slightly lower $\mathrm{FEV}_{1}$ and $\mathrm{FEV}_{1} / \mathrm{FVC}$ values than those excluded. There were no differences in hormone levels.

\section{Lung function with hormone measures at baseline}

Associations of lung function with hormonal measures at baseline are shown in table 2 .

In men, higher TT was associated with higher $\mathrm{FEV}_{1}$ and higher FVC. Although not statistically significant, effect estimates for cFT were in a similar direction. There was strong evidence that the association of cFT levels with $\mathrm{FEV}_{1}$ and $\mathrm{FVC}$ in men was modified by physical activity (for interaction, $\mathrm{p}=0.029$ and $\mathrm{p}=0.026$, respectively). Stronger positive associations were observed in men physically active for more than 3 days per week (mean difference in $\mathrm{FEV}_{1}$ per IQR change in cFT: $36.73 \mathrm{~mL}, 95 \%$ CI 4.69-68.77; FVC: $42.77 \mathrm{~mL}$, 95\% CI 4.92-80.62) compared to less-active men $\left(\mathrm{FEV}_{1}\right.$ : $-10.15 \mathrm{~mL}, 95 \% \mathrm{CI}-35.07$ to 14.77 ; FVC: $-13.94,95 \%$ CI -43.14 to 15.25$)$.

In women, there was a negative association of $\mathrm{FAI}$ with $\mathrm{FEV}_{1}$ and $\mathrm{FVC}$, which, unlike in men, reached conventional levels of significance for FVC.

Higher levels of TT, FAI or cFT were not associated with airway obstruction $\left(\mathrm{FEV}_{1} / \mathrm{FVC}\right.$ ratio) in either sex.

Men and women with higher SHBG levels had higher FEV 1 and FVC. Effect sizes were higher in men than in women and higher for FVC than for $\mathrm{FEV}_{1}$. Consequently, there was some evidence of an inverse association of SHBG with the $\mathrm{FEV}_{1} / \mathrm{FVC}$ ratio in men $(-0.33 \%, 95 \% \mathrm{CI}-0.58$ to -0.07$)$.

Repeating analyses on all participants with reproducible and acceptable quality spirometry at baseline only and on all participants at baseline, irrespective of spirometry quality did not change the findings (supplemental tables S1 and S2).

\section{Lung function decline with hormone measures at baseline}

Associations of lung function decline over the 8-year follow-up with hormonal measurements at baseline are shown in table 3 .

Few associations were observed, and all effect estimates were small.

Men with higher SHBG had greater decline in all lung function parameters.

Women with higher TT, FAI and cFT had less FVC and $\mathrm{FEV}_{1}$ decline. Higher cFT levels were also associated with less FVC decline. There were no associations with $\mathrm{FEV}_{1} / \mathrm{FVC}$. Unlike in men, there was no association of lung function decline with SHBG in women.

Results were broadly similar when all participants with available spirometry at baseline and the 8-year follow-up were included, regardless of spirometry quality (supplemental table S3).

Adjusting the longitudinal model for baseline lung function led to slightly stronger effect sizes for men (supplemental table S4).

No differences in the cross-sectional or longitudinal results were found when women with self-reported polycystic ovary syndrome (PCOS) $(n=18)$ or men with prostate cancer or prostate hypertrophy $(n=584)$ were excluded (supplemental tables S5 and S6).

No differences in cross-sectional or longitudinal results were found when participants with self-reported asthma or emphysema/chronic bronchitis at baseline ( $n=1230$ and $n=36$, respectively) and follow-up (additionally, $\mathrm{n}=268$ and $\mathrm{n}=37$, respectively) were excluded. 
TABLE 1 Characteristics of participants who had spirometry at baseline and follow-up and biomarker measurements at baseline

\begin{tabular}{|c|c|c|c|c|c|c|c|c|}
\hline & \multicolumn{3}{|c|}{ High-quality spirometry (included participants) } & \multicolumn{3}{|c|}{ Low-quality spirometry (excluded participants) } & \multicolumn{2}{|c|}{$\begin{array}{l}\text { Differences between included } \\
\text { and excluded participants }\end{array}$} \\
\hline & $\begin{array}{c}\text { Male } n=5114 \\
(48.3 \%)\end{array}$ & $\begin{array}{c}\text { Female } n=5467 \\
(51.7 \%)\end{array}$ & p-value ${ }^{\#}$ & $\begin{array}{c}\text { Male } n=7067 \\
\quad(55.7 \%)\end{array}$ & $\begin{array}{c}\text { Female } n=5622 \\
(44.3 \%)\end{array}$ & p-value ${ }^{\#}$ & $\begin{array}{c}\text { p-value } \\
\text { men }\end{array}$ & $\begin{array}{l}\text { p-value } \\
\text { women }\end{array}$ \\
\hline Age years & $55.3 \pm 7.6$ & $53.5 \pm 7.1$ & $<0.001$ & $55.4 \pm 7.6$ & $54.0 \pm 7.5$ & $<0.001$ & 0.703 & $<0.001$ \\
\hline Smoking & & & $<0.001$ & & & $<0.001$ & $<0.001$ & $<0.001$ \\
\hline Never & $2776(54.4)$ & 3426 (62.8) & & $4186(59.4)$ & $3790(67.6)$ & & & \\
\hline Ex & $1938(38.0)$ & 1729 (31.7) & & $2369(33.6)$ & $1526(27.2)$ & & & \\
\hline Current & $387(7.6)$ & $304(5.6)$ & & $496(7.0)$ & $292(5.2)$ & & & \\
\hline Pack-years $^{+}$ & $21.0 \pm 16.4$ & $16.6 \pm 12.9$ & $<0.001$ & $21.3 \pm 17.7$ & $15.9 \pm 12.3$ & $<0.001$ & 0.654 & 0.176 \\
\hline BMI & $27.2 \pm 3.8$ & $26.3 \pm 4.7$ & $<0.001$ & $27.2 \pm 3.8$ & $26.2 \pm 4.7$ & $<0.001$ & 0.923 & 0.083 \\
\hline Townsend deprivation index & $-2.1 \pm 2.6$ & $-2.0 \pm 2.6$ & 0.147 & $-1.97 \pm 2.7$ & $-1.84 \pm 2.7$ & 0.006 & 0.012 & $<0.001$ \\
\hline $\begin{array}{l}\text { Moderate physical activity" } \\
\text { days }^{\text {"week }}{ }^{-1}\end{array}$ & $3.4 \pm 2.2$ & $3.5 \pm 2.3$ & 0.057 & $3.4 \pm 2.3$ & $3.5 \pm 2.3$ & 0.062 & 0.428 & 0.362 \\
\hline Daily fresh fruit intake & & & $<0.001$ & & & $<0.001$ & 0.003 & 0.251 \\
\hline 0-1 portion & $2162(42.4)$ & 1603 (29.3) & & 2783 (39.4) & $1615(28.8)$ & & & \\
\hline 2-3 portions & $2253(44.2)$ & 2910 (53.2) & & 3235 (45.9) & $3070(54.7)$ & & & \\
\hline$>3$ portions & $685(13.4)$ & $954(17.5)$ & & $1038(14.7)$ & 928 (16.5) & & & \\
\hline Length of follow-up years & $8.6(7.2$ to 9.7$)$ & $8.6(7.2$ to 9.7$)$ & 0.242 & $8.4(7.1$ to 9.6$)$ & $8.4(7.1$ to 9.6$)$ & 0.804 & 0.127 & 0.004 \\
\hline \multicolumn{9}{|l|}{ Lung function parameters } \\
\hline FEV 1 L & 3.46 (3.05 to 3.89 ) & 2.58 (2.27 to 2.89 ) & $<0.001$ & 3.55 (3.15 to 3.96 ) & 2.60 (2.30 to 2.91$)$ & $<0.001$ & $<0.001$ & 0.020 \\
\hline FVC L & $4.56(4.06$ to 5.10$)$ & 3.35 (2.97 to 3.75$)$ & $<0.001$ & $4.63(4.12$ to 5.14$)$ & 3.34 (2.97 to 3.72$)$ & $<0.001$ & 0.001 & 0.725 \\
\hline $\mathrm{FEV}_{1} / \mathrm{FVC} \%$ & 76.4 (72.3 to 79.8 ) & 77.3 (73.9 to 80.3$)$ & $<0.001$ & 77.4 (73.6 to 80.5$)$ & $78.2(75.2$ to 81.1$)$ & $<0.001$ & $<0.001$ & $<0.001$ \\
\hline \multicolumn{9}{|l|}{ Serum measures } \\
\hline SHBG nmol. $\mathrm{L}^{-1}$ & 36.9 (27.7 to 47.7 ) & $59.0(42.5$ to 79.4$)$ & $<0.001$ & 36.5 (27.7 to 47.4$)$ & 59.4 (42.5 to 79.9 ) & $<0.001$ & 0.674 & 0.538 \\
\hline TT nmol. $\mathrm{L}^{-1}$ & 11.9 (9.7 to 14.3 ) & $1.0(0.7$ to 1.4$)$ & $<0.001$ & 11.9 (9.7 to 14.2$)$ & $1.0(0.7$ to 1.4$)$ & $<0.001$ & 0.428 & 0.633 \\
\hline FAl & $32.0(26.0$ to 40.1$)$ & 1.7 (1.1 to 2.7$)$ & $<0.001$ & 32.1 (26.2 to 40.1$)$ & 1.7 (1.1 to 2.7$)$ & $<0.001$ & 0.733 & 0.854 \\
\hline $\mathrm{CFT} \mathrm{nmol} \cdot \mathrm{L}^{-1}$ & 0.21 (0.18 to 0.25 ) & $0.01(0.01$ to 0.02$)$ & $<0.001$ & 0.21 (0.18 to 0.25 ) & $0.01(0.01$ to 0.02$)$ & $<0.001$ & 0.789 & 0.814 \\
\hline
\end{tabular}

Data are presented as mean $\pm \mathrm{SD}, \mathrm{n}(\%)$ or median (interquartile range), unless otherwise stated. BMI: body mass index; IQR: interquartile range; $F E V_{1}$ : forced expiratory volume in $1 \mathrm{~s}$;

FVC: forced vital capacity; SHBG: sex hormone-binding globulin; TT: total testosterone; FAI: free androgen index; cFT: calculated free testosterone; n/a: not appropriate to derive.

\#: Statistical difference between men and women tested through two-sample t-test for continuous variables and Chi-squared test for categorical variables; ": minimum 10 min;

${ }^{+}$: calculated amongst ever-smokers only. 
TABLE 2 Difference in forced expiratory volume in 1 second $\left(\mathrm{FEV}_{1}\right)$ and forced vital capacity (FVC) $(\mathrm{mL})$ and $\mathrm{FEV} / \mathrm{FVC}(\%)$ at baseline in men and women per sex-specific interquartile range increase in hormone measure

\begin{tabular}{|c|c|c|c|c|c|c|}
\hline \multirow[t]{3}{*}{ Hormonal measure } & \multicolumn{3}{|c|}{ Men } & \multicolumn{3}{|c|}{ Women } \\
\hline & \multicolumn{3}{|c|}{$n=4252^{\#}$} & \multicolumn{3}{|c|}{$n=4616^{\#}$} \\
\hline & $\mathrm{FEV}_{1} \mathrm{~mL}$ & FVC mL & FEV $_{1} /$ FVC $\%$ & $\mathrm{FEV}_{1} \mathrm{~mL}$ & FVC $\mathrm{mL}$ & FEV $_{1} /$ FVC $\%$ \\
\hline TT & 27.56 (5.43 to 49.68$)$ & 48.06 (22.07 to 74.06$)$ & $-0.18(-0.42$ to 0.07$)$ & $4.22(-6.60$ to 15.04$)$ & $1.51(-11.67$ to 14.70$)$ & $0.08(-0.06$ to 0.22$)$ \\
\hline FAI & $-3.20(-21.86$ to 15.47$)$ & $-15.47(-37.41$ to 6.47$)$ & $0.17(-0.04$ to 0.38$)$ & $-7.67(-15.72$ to 0.37$)$ & $-12.47(-22.27$ to -2.67$)$ & $0.05(-0.06$ to 0.15$)$ \\
\hline cFT & $8.42(-11.26$ to 28.10$)$ & $8.10(-15.04$ to 31.24$)$ & $0.03(-0.18$ to 0.25$)$ & $-7.15(-17.68$ to 3.38$)$ & $-12.27(-25.10$ to 0.55$)$ & $0.05(-0.08$ to 0.19$)$ \\
\hline SHBG & 26.74 (3.81 to 49.68 ) & 57.76 (30.83 to 84.69$)$ & $-0.33(-0.58$ to -0.07$)$ & 16.83 (2.18 to 31.48$)$ & $28.87(11.03$ to 46.71$)$ & $-0.11(-0.30$ to 0.07$)$ \\
\hline
\end{tabular}

All results are expressed in millilitres $(\mathrm{mL})$ for average changes in $\mathrm{FEV}_{1}$ and $\mathrm{FVC}$ levels and as percentages (\%) for the $\mathrm{FEV} / \mathrm{FVC}$ ratio, with corresponding $95 \%$ Cl. Participants with hormonal biomarker measurements and high-quality spirometry available at both time points. Linear regression model adjusted for age, age ${ }^{2}$, standing height, body mass index, smoking status, pack-years, Townsend deprivation score, days per week of moderate physical activity, fresh fruit intake and time of appointment. FEV $\mathrm{F}_{1}$ : forced expiratory volume in $1 \mathrm{~s}_{\text {; }}$ FVC: forced vital capacity; TT: total testosterone; FAl: free androgen index; cFT: calculated free testosterone; SHBG: sex hormone-binding globulin. ${ }^{\#}$ : numbers of participants with no covariates missing for the adjusted model. Bold text indicates a $95 \% \mathrm{Cl}$ not overlapping 0.

TABLE 3 Difference in decline in forced expiratory volume in 1 second $\left(\mathrm{FEV}_{1}\right)$ and forced vital capacity $(\mathrm{FVC})\left(\mathrm{mL} \cdot \mathrm{yr} \mathrm{r}^{-1}\right)$ and $\mathrm{FEV} / \mathrm{FVC}\left(\% \cdot \mathrm{yr}{ }^{-1}\right)$ in $\mathrm{men}$ and women per sex-specific interquartile range increase in hormone level measured at baseline

\begin{tabular}{|c|c|c|c|c|c|c|}
\hline \multirow[t]{3}{*}{ Hormonal measure } & \multicolumn{3}{|c|}{ Men } & \multicolumn{3}{|c|}{ Women } \\
\hline & \multicolumn{3}{|c|}{$\mathrm{n}=4333^{\#}$} & \multicolumn{3}{|c|}{$\mathrm{n}=4734^{\#}$} \\
\hline & $\mathrm{FEV}_{1} \mathrm{~mL} \cdot \mathrm{yr} \mathrm{r}^{-1}$ & $\mathrm{FVC} \mathrm{mL} \cdot \mathrm{yr}^{-1}$ & $\mathrm{FEV}_{1} / \mathrm{FVC} \% \cdot \mathrm{yr}^{-1}$ & $\mathrm{FEV}_{1} \mathrm{~mL} \cdot \mathrm{yr}^{-1}$ & $\mathrm{FVC} \mathrm{mL} \cdot \mathrm{yr}^{-1}$ & $\mathrm{FEV}_{1} / \mathrm{FVC}^{2} \cdot \mathrm{yr}^{-1}$ \\
\hline TT & $-0.91(-2.66$ to 0.84$)$ & $-0.24(-2.38$ to 1.89$)$ & $-0.02(-0.04$ to 0.00$)$ & $0.98(0.00$ to 1.95$)$ & $1.38(0.18$ to 2.59$)$ & $0.00(-0.01$ to 0.01$)$ \\
\hline FAI & $1.04(-0.39$ to 2.47$)$ & $1.46(-0.28$ to 3.20$)$ & $0.01(-0.01$ to 0.03$)$ & $0.77(0.10$ to 1.44$)$ & $1.03(0.20$ to 1.86$)$ & $0.00(-0.01$ to 0.01$)$ \\
\hline cFT & $0.76(-0.82$ to 2.34$)$ & $1.55(-0.37$ to 3.47$)$ & $-0.00(-0.02$ to 0.02$)$ & $1.00(0.12$ to 1.89$)$ & $1.45(0.36$ to 2.55$)$ & $-0.00(-0.01$ to 0.01$)$ \\
\hline SHBG & $-2.69(-4.44$ to -0.95$)$ & $-2.76(-4.88$ to -0.63$)$ & $-0.03(-0.05$ to -0.01$)$ & $-0.50(-1.66$ to 0.66$)$ & $-0.77(-2.20$ to 0.66$)$ & -0.00 l -0.02 to 0.02 \\
\hline
\end{tabular}

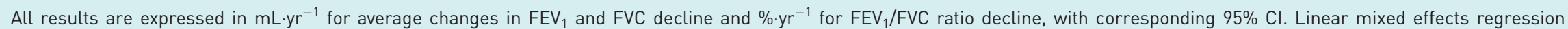
model adjusted for age, age ${ }^{2}$, standing height, body mass index, smoking status, pack-years, Townsend deprivation score, days per week of moderate physical activity, fresh fruit intake, time of appointment and a random intercept for participant. FEV ${ }_{1}$ : forced expiratory volume in $1 \mathrm{~s}$; FVC: forced vital capacity; TT: total testosterone; FAl: free androgen index; cFT: calculated free testosterone; SHBG: sex hormone-binding globulin. ${ }^{\#}$ : numbers of participants with no covariates missing for the adjusted model. Bold text indicates a $95 \% \mathrm{Cl}$ not overlapping 0. 


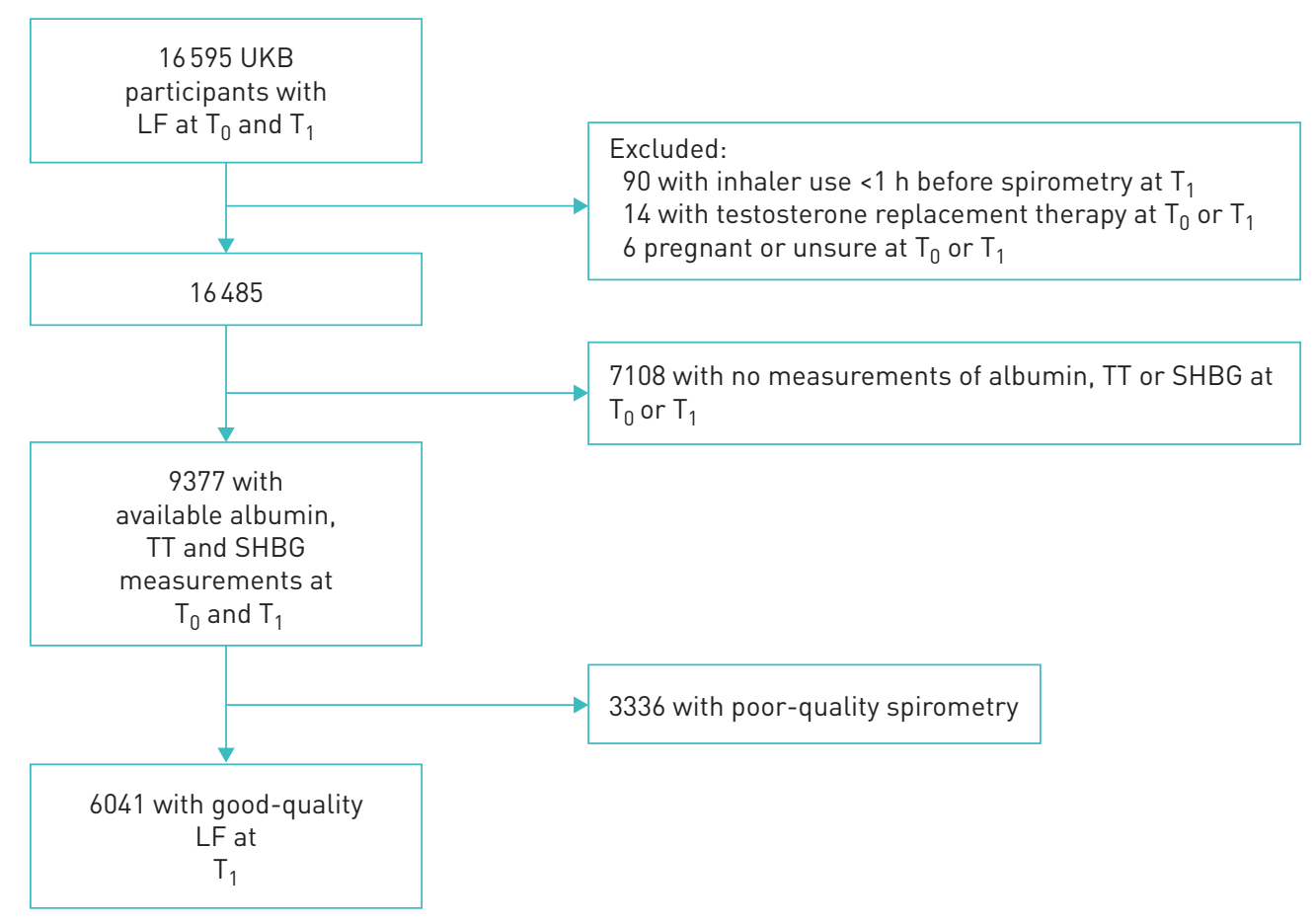

FIGURE 2 Flow chart of TO - T1 participants with acceptable and reproducible spirometry at first follow-up (T1, 2012-2013) and available measurements for TT, SHBG and albumin at both baseline (T0, 2006-2010) and T1. LF: lung function; SHBG: sex hormone-binding globulin; TT: total testosterone; UKB: UK Biobank.

\section{Change in hormones and lung function}

There were 16595 subjects with spirometry at $T_{0}$ and at $T_{1}$ (mean 4.3 years later) (figure 2), of which 6041 had hormonal measures on both occasions and good-quality spirometry at first follow-up.

The mean, median and IQR of baseline values and change in each hormonal measure over the 4-year period are shown in table 4. FAI and cFT levels decreased in men more than women. SHBG levels

\section{TABLE 4 Hormonal biomarkers between baseline (2006-2010) and first follow-up (2012-2013)}

\begin{tabular}{|c|c|c|c|c|c|c|}
\hline $\begin{array}{l}\text { Hormonal } \\
\text { measure }\end{array}$ & $\begin{array}{l}\text { Men ( } n=3342 \text { ) } \\
\text { baseline }\end{array}$ & $\begin{array}{l}\text { Change by } \\
\text { follow-up" }\end{array}$ & $\begin{array}{l}\text { p-value for } \\
\text { change }^{\pi}\end{array}$ & $\begin{array}{c}\text { Women ( } \mathrm{n}=2699 \text { ) } \\
\text { baseline }\end{array}$ & $\begin{array}{l}\text { Change by } \\
\text { follow-up" }\end{array}$ & $\begin{array}{l}\text { p-value for } \\
\text { change }^{\pi}\end{array}$ \\
\hline \multicolumn{7}{|l|}{ TT } \\
\hline Median & 12.00 & 0.06 & & 1.05 & -0.01 & \\
\hline IQR & 9.87 to 14.32 & -1.71 to 1.75 & & 0.77 to 1.39 & -0.24 to 0.24 & \\
\hline \multicolumn{7}{|l|}{ FAl } \\
\hline IQR & 25.48 to 39.15 & -7.44 to 2.24 & & 1.16 to 2.88 & -0.56 to 0.44 & \\
\hline \multicolumn{7}{|l|}{ cFT } \\
\hline Mean & 0.216 & -0.011 & $<0.001$ & 0.015 & -0.000 & 0.006 \\
\hline Median & 0.210 & -0.010 & & 0.013 & -0.000 & \\
\hline IQR & 0.176 to 0.248 & -0.044 to 0.020 & & 0.009 to 0.019 & -0.004 to 0.003 & \\
\hline \multicolumn{7}{|l|}{ SHBG } \\
\hline
\end{tabular}


increased over time in both sexes. TT levels were not different between baseline and first follow-up, hence associations between changes in this parameter and lung function were not considered.

Table 5 shows the association of lung function at $\mathrm{T}_{1}$ with hormonal changes between $\mathrm{T}_{0}$ and $\mathrm{T}_{1}$. Hormonal changes are expressed as sex-specific quartiles of difference between the measurements $\left(\mathrm{T}_{1}-\mathrm{T}_{0}\right)$.

There was no association of change in FAI or cFT with lung function after 4 years in men. Although some associations were observed in women for FAI and $\mathrm{cFT}$, there was no evidence of linearity and consistency (trend $\mathrm{p}=0.283$ for $\mathrm{FEV}_{1}$ and FAI; $\mathrm{p}=0.078$ for FVC and FAI; trend $\mathrm{p}=0.252$ for $\mathrm{FEV}_{1}$ and $\mathrm{cFT}$; $\mathrm{p}=0.152$ for FVC and cFT).

Being in the quartile with the greatest increase (Q4) in SHBG was associated with higher $\mathrm{FEV}_{1}$ in men (trend $\mathrm{p}=0.031$ across all quartiles), higher FVC in both sexes (trend $\mathrm{p}=0.002$ in men, $\mathrm{p}=0.004$ in women) but more airway obstruction in both sexes (trend $\mathrm{p}=0.035$ in men, $\mathrm{p}<0.001$ in women) at follow-up.

Excluding women with self-reported PCOS or men with prostate cancer or prostate hypertrophy did not change the results. Effect estimates were slightly attenuated when the adjustments for lung function and testosterone at $\mathrm{T}_{0}$ were removed.

\section{Discussion}

In the largest study to date, we found that men with higher levels of TT had better lung function. Higher levels of bioavailable testosterone ( $\mathrm{cFT}$ ) were also associated with better lung function in physically active men. These results are consistent with previous work suggesting better lung function in men with more bioavailable testosterone (measured by cFT [21] and dihydrotestosterone [22]), although these earlier studies did not consider effect modification by physical activity. Nonetheless, effect modification by physical activity is supported by some small randomised controlled trials of TRT that suggest that beneficial effects are mainly seen in those taking part in a pulmonary rehabilitation programme incorporating exercise. This is biologically plausible as androgens have a positive effect on respiratory muscle strength, and physical activity is associated with better lung function [23, 24].

Our analysis is the first to include women and shows some important differences to men. The lack of cross-sectional associations between TT and lung function in women could be partly due to 10-fold lower TT concentrations compared to men. Our study further suggests that bioavailable androgens (FAI, cFT) have deleterious associations with lung function. This observation is consistent with reports of poor lung function in women with PCOS [25], a condition characterised by high androgen levels [26]. Excluding those with self-reported PCOS did not alter the results, but this condition is frequently undiagnosed [27]. The menopausal transition and menopause do not have an independent impact on testosterone levels in women [28] and adjustment for proxy measures of menopausal status did not alter the associations observed (data not shown).

This study is the first report of associations of testosterone levels with lung function decline, for which we found little evidence, despite the strong cross-sectional associations. We propose several potential interpretations. First, testosterone could have short-term effects on lung function rather than influencing decline. Second, current testosterone levels may reflect levels across the life course, and associations in adults reflect positive influences on lung growth earlier in life. Both known forms of the androgen receptor are expressed in the adult human lung, predominantly in the epithelium and type II pneumocytes [29]. Androgen exposure influences the gene expression profile in mouse models and human lung adenocarcinoma tissue, upregulating genes involved in oxygen transport and downregulating genes implicated in DNA repair [29]. This could mediate greater lung growth in early life or adolescence without impacting on decline. Third, given that we only had two measures of lung function and very small effect sizes were observed, regression to the mean may have occurred. This may also account for the small associations between reduced $\mathrm{FEV}_{1}$ and FVC decline over 8 years with levels of TT, FAI and cFT at baseline in women.

Finally, our study found clear evidence that both men and women with higher levels of SHBG had better lung function, after controlling for obesity. In addition, participants whose SHBG levels increased most over a 4-year period had higher $\mathrm{FEV}_{1}$ and FVC at the end of this period. SHBG is synthesised in the liver, binds to testosterone, dihydrotestosterone and oestrogen and is the major plasma transport protein for these hormones [30]. It tightly controls the levels of free or bioavailable testosterone [31] but has been negatively associated with obesity and risk for type 2 diabetes [32], both associated with decreased lung function $[33,34]$. Thus, SHBG links hormonal with metabolic status while being associated with lung health as recently shown in a Mendelian randomisation study [35]. 
TABLE 5 Difference in forced expiratory volume in 1 second $\left(F E V_{1}\right)$ and forced vital capacity (FVC) $(\mathrm{mL})$ and $\mathrm{FEV}_{1} / \mathrm{FVC}(\%)$ at first follow-up per sex-specific quartile of difference between hormone level measured at baseline (2006-2010) and first follow-up (2012-2013)

\begin{tabular}{|c|c|c|c|c|c|c|}
\hline \multirow{3}{*}{$\begin{array}{l}\Delta \text { Hormonal } \\
\text { measure }\end{array}$} & \multicolumn{3}{|c|}{ Men } & \multicolumn{3}{|c|}{ Women } \\
\hline & \multicolumn{3}{|c|}{$n={ }^{\#} 1907$} & \multicolumn{3}{|c|}{$n={ }^{\# 1764}$} \\
\hline & $\mathrm{FEV}_{1}(\mathrm{~mL})$ & FVC (mL) & $\mathrm{FEV}_{1} / \mathrm{FVC}(\%)$ & $\mathrm{FEV}_{1}(\mathrm{~mL})$ & FVC (mL) & $\mathrm{FEV}_{1} / \mathrm{FVC}(\%)$ \\
\hline \multicolumn{7}{|l|}{ FAI } \\
\hline Quartile 2 & $-30.53(-77.63$ to 16.58$)$ & $-27.78(-86.95$ to 31.39$)$ & $-0.10(-0.54$ to 0.33$)$ & $-46.31(-81.28$ to -11.34$)$ & $-66.27(-109.57$ to -22.97$)$ & $0.15(-0.38$ to 0.67$)$ \\
\hline Quartile 3 & $-20.06(-69.03$ to 28.91$)$ & $-27.32(-88.83$ to 34.20$)$ & $0.12(-0.33$ to 0.58$)$ & $-38.76(-74.35$ to -3.16$)$ & $-37.74(-81.83$ to 6.36$)$ & $-0.33(-0.87$ to 0.20$)$ \\
\hline Quartile 4 & $-8.98(-58.11$ to 40.14$)$ & $-20.27(-81.97$ to 41.44$)$ & $0.18(-0.28$ to 0.63$)$ & $-34.46(-68.74$ to -0.18$)$ & $-54.10(-96.55$ to -11.64$)$ & $0.18(-0.33$ to 0.69$)$ \\
\hline \multicolumn{7}{|c|}{ 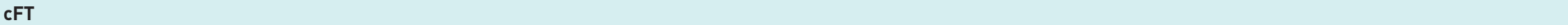 } \\
\hline Quartile 2 & 7.73 (-38.78 to 54.25$)$ & $-2.94(-61.35$ to 55.47$)$ & $0.24(-0.19$ to 0.67$)$ & $-42.23(-76.75$ to -7.71$)$ & $-62.44(-105.21$ to -19.67$)$ & $0.20(-0.32$ to 0.72$)$ \\
\hline Quartile 3 & $-7.17(-55.07$ to 40.73$)$ & $-14.06(-74.23$ to 46.10$)$ & $0.16(-0.28$ to 0.61$)$ & $-36.58(-71.86$ to -1.30$)$ & $-35.80(-79.51$ to 7.91$)$ & $-0.28(-0.81$ to 0.25$)$ \\
\hline Quartile 4 & 29.54 (-20.68 to 79.77$)$ & $24.31(-38.78$ to 87.39$)$ & $0.29(-0.18$ to 0.75$)$ & $-31.92(-66.52$ to 2.68$)$ & $-46.52(-89.39$ to -3.66$)$ & $0.07(-0.45$ to 0.59$)$ \\
\hline \multicolumn{7}{|l|}{ SHBG } \\
\hline Quartile 2 & $17.98(-28.46$ to 64.41$)$ & $47.44(-10.67$ to 105.55$)$ & $-0.43(-0.85$ to 0.00$)$ & -27.56 (-61.83 to 6.72$)$ & $-9.55(-51.94$ to 32.85$)$ & $-0.65(-1.16$ to -0.14$)$ \\
\hline Quartile 3 & $32.56(-13.43$ to 78.55$)$ & $69.56(11.92$ to 127.20$)$ & $-0.46(-0.89$ to -0.04$)$ & $-29.71(-64.08$ to 4.66$)$ & $-7.96(-50.43$ to 34.50$)$ & $-0.77(-1.29$ to -0.26$)$ \\
\hline Quartile 4 & 47.47 (2.36 to 92.59$)$ & 89.06 (32.56 to 145.57$)$ & $-0.47(-0.89$ to -0.06$)$ & 9.02 (-24.37 to 42.42$)$ & $59.30(17.97$ to 100.62$)$ & $-1.18(-1.68$ to -0.68$)$ \\
\hline \multicolumn{7}{|c|}{ 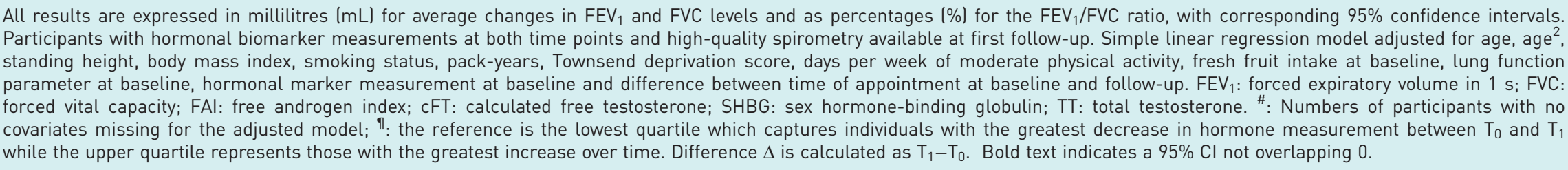 } \\
\hline
\end{tabular}


The strengths of this study are its large sample size, measures in both sexes and the examination of longitudinal associations. However, with such a large study small effect sizes that reach statistical significance can be observed, although they may be clinically irrelevant (as seen in the analysis of change over an 8-year period). The 8-year follow-up is relatively short; it is possible that trends would become clearer in studies with longer follow-ups.

One difficulty in the interpretation of our results lies in the various available measures of testosterone. Most circulating testosterone is strongly bound to SHBG, some weakly bound to albumin and approximately $2-3 \%$ circulating freely in the serum [36]. The free component is active and able to bind the androgen receptor of target tissues to exert androgenic effects [37]. However, the reference methods to measure free testosterone are equilibrium dialysis and ultrafiltration, which are analytically and technically challenging and rarely performed in clinical laboratories [38]. The FAI is a simple method to estimate bioavailable testosterone levels and widely used in clinical practice and research. However, when SHBG concentrations are low, it correlates less well with the gold standard measurements of free testosterone $[19,39]$. Therefore, alternative methods to calculate free testosterone ( $\mathrm{cFT}$ ) have been developed the most widely adopted being the method of Vermeulen [19,38]. Further, total and free testosterone levels show marked diurnal variation with peaks between 05:30 and 08:00. To avoid measurement error, blood samples should be collected in the early morning [22] or the analysis adjusted for the time of collection, as we and others [21] have done.

We excluded participants reporting inhaler use in the hour preceding spirometry, thereby removing any immediate effects of inhalers on lung function. Participants with poorer lung function may be more likely to use inhalers on a regular basis (but not in the hour before spirometry), which may have led to an underestimation of the effects of testosterone on lung function.

UK Biobank participants are not representative of the UK general population, with evidence of a "healthy volunteer" selection bias [40]. This should not compromise the generalisability of observed associations unless the group of nonresponders had different associations of lung function with the hormonal measures than responders, which seems unlikely.

We conclude that men, but not women, with higher levels of TT have better lung function. We also observe that the effect of cFT on lung function may be restricted to physically active men. In women, higher levels of bioavailable testosterone seem associated with worse lung function. The strong associations of SHBG with lung function in both sexes warrant further investigation.

Conflict of interest: None declared.

Support statement: A. Lenoir was supported by the Ligue Pulmonaire Vaudoise and by the Fond de perfectionnement du Centre Hospitalier Universitaire Vaudois. D. A. van der Plaat has received funding from the ERS and the European Union's H2020 Research and Innovation Programme under the Marie Sklodowska-Curie grant agreement no. 713406. E. Fuertes is a recipient of an Imperial College Research Fellowship. Funding information for this article has been deposited with the Crossref Funder Registry.

\section{References}

1 Atlantis E, Fahey P, Cochrane B, et al. Endogenous testosterone level and testosterone supplementation therapy in chronic obstructive pulmonary disease (COPD): a systematic review and meta-analysis. BMJ Open 2013; 3 : e003127.

2 Casaburi R, Bhasin S, Cosentino L, et al. Effects of testosterone and resistance training in men with chronic obstructive pulmonary disease. Am J Respir Crit Care Med 2004; 170: 870-878.

3 Creutzberg EC, Wouters EF, Mostert R, et al. A role for anabolic steroids in the rehabilitation of patients with COPD? A double-blind, placebo-controlled, randomized trial. Chest 2003; 124: 1733-1742.

4 Ferreira IM, Verreschi IT, Nery LE, et al. The influence of 6 months of oral anabolic steroids on body mass and respiratory muscles in undernourished COPD patients. Chest 1998; 114: 19-28.

5 Sharma S, Arneja A, McLean L, et al. Anabolic steroids in COPD: a review and preliminary results of a randomized trial. Chron Respir Dis 2008; 5: 169-176.

6 Svartberg J, Aasebo U, Hjalmarsen A, et al. Testosterone treatment improves body composition and sexual function in men with COPD, in a 6-month randomized controlled trial. Respir Med 2004; 98: 906-913.

7 Torday JS, Nielsen HC. The sex difference in fetal lung surfactant production. Exp Lung Res 1987; 12: 1-19.

8 Seaborn T, Simard M, Provost PR, et al. Sex hormone metabolism in lung development and maturation. Trends Endocrinol Metab 2010; 21: 729-738.

9 Sathish V, Martin YN, Prakash YS. Sex steroid signaling: implications for lung diseases. Pharmacol Ther 2015; 150: 94-108.

10 Horstman AM, Dillon EL, Urban RJ, et al. The role of androgens and estrogens on healthy aging and longevity. J Gerontol A Biol Sci Med Sci 2012; 67: 1140-1152.

11 Feldman HA, Longcope C, Derby CA, et al. Age trends in the level of serum testosterone and other hormones in middle-aged men: longitudinal results from the Massachusetts male aging study. J Clin Endocrinol Metab 2002; 87: $589-598$. 
12 Goodman-Gruen D, Barrett-Connor E. Sex differences in the association of endogenous sex hormone levels and glucose tolerance status in older men and women. Diabetes Care 2000; 23: 912-918.

13 Zumoff B, Strain GW, Miller LK, et al. Twenty-four-hour mean plasma testosterone concentration declines with age in normal premenopausal women. J Clin Endocrinol Metab 1995; 80: 1429-1430.

14 Burger HG, Dudley EC, Cui J, et al. A prospective longitudinal study of serum testosterone, dehydroepiandrosterone sulfate, and sex hormone-binding globulin levels through the menopause transition. J Clin Endocrinol Metab 2000; 85: 2832-2838.

15 Morley JE, Perry HM 3rd,. Androgens and women at the menopause and beyond. J Gerontol A Biol Sci Med Sci 2003; 58: M409-M416.

16 Miller MR, Hankinson J, Brusasco V, et al. Standardisation of spirometry. Eur Respir J 2005; 26: 319-338.

17 Selby C. Sex hormone binding globulin: origin, function and clinical significance. Ann Clin Biochem 1990; 27: Pt. 6, 532-541.

18 Simo R, Saez-Lopez C, Barbosa-Desongles A, et al. Novel insights in SHBG regulation and clinical implications. Trends Endocrinol Metab 2015; 26: 376-383.

19 Ho CK, Stoddart M, Walton M, et al. Calculated free testosterone in men: comparison of four equations and with free androgen index. Ann Clin Biochem 2006; 43: Pt. 5, 389-397.

20 Townsend P. Deprivation. J Soc Policy 1987; 16: 125-146.

21 Svartberg J, Schirmer H, Medbo A, et al. Reduced pulmonary function is associated with lower levels of endogenous total and free testosterone. The Tromso study. Eur J Epidemiol 2007; 22: 107-112.

22 Mohan SS, Knuiman MW, Divitini ML, et al. Higher serum testosterone and dihydrotestosterone, but not oestradiol, are independently associated with favourable indices of lung function in community-dwelling men. Clin Endocrinol (Oxf) 2015; 83: 268-276.

23 Fuertes E, Carsin AE, Anto JM, et al. Leisure-time vigorous physical activity is associated with better lung function: the prospective ECRHS study. Thorax 2018; 73: 376-384.

24 Luzak A, Karrasch S, Thorand B, et al. Association of physical activity with lung function in lung-healthy German adults: results from the KORA FF4 study. BMC Pulm Med 2017; 17: 215.

25 Real FG, Svanes C, Omenaas ER, et al. Menstrual irregularity and asthma and lung function. J Allergy Clin Immunol 2007; 120: 557-564.

26 Legro RS, Arslanian SA, Ehrmann DA, et al. Diagnosis and treatment of polycystic ovary syndrome: an Endocrine Society clinical practice guideline. J Clin Endocrinol Metab 2013; 98: 4565-4592.

27 Sirmans SM, Parish RC, Blake S, et al. Epidemiology and comorbidities of polycystic ovary syndrome in an indigent population. J Investig Med 2014; 62: 868-874.

28 Davison SL, Bell R, Donath S, et al. Androgen levels in adult females: changes with age, menopause, and oophorectomy. J Clin Endocrinol Metab 2005; 90: 3847-3853.

29 Mikkonen L, Pihlajamaa P, Sahu B, et al. Androgen receptor and androgen-dependent gene expression in lung. Mol Cell Endocrinol 2010; 317: 14-24.

30 Hammond GL. Diverse roles for sex hormone-binding globulin in reproduction. Biol Reprod 2011; 85: 431-441.

31 Hammond GL. Plasma steroid-binding proteins: primary gatekeepers of steroid hormone action. J Endocrinol 2016; 230: R13-R25.

32 Ding EL, Song Y, Manson JE, et al. Sex hormone-binding globulin and risk of type 2 diabetes in women and men. N Engl J Med 2009; 361: 1152-1163.

33 Walter RE, Beiser A, Givelber RJ, et al. Association between glycemic state and lung function: the Framingham Heart Study. Am J Respir Crit Care Med 2003; 167: 911-916.

34 Lange P, Groth S, Kastrup J, et al. Diabetes mellitus, plasma glucose and lung function in a cross-sectional population study. Eur Respir J 1989; 2: 14-19.

35 Arathimos R, Granell R, Haycock P, et al. Genetic and observational evidence supports a causal role of sex hormones on the development of asthma. Thorax 2019; 74: 633-642.

36 Dunn JF, Nisula BC, Rodbard D. Transport of steroid hormones: binding of 21 endogenous steroids to both testosterone-binding globulin and corticosteroid-binding globulin in human plasma. J Clin Endocrinol Metab 1981; 53: 58-68.

37 Keevil BG, Adaway J. Assessment of free testosterone concentration. J Steroid Biochem Mol Biol 2019; 190: $207-211$

38 Vermeulen A, Verdonck L, Kaufman JM. A critical evaluation of simple methods for the estimation of free testosterone in serum. J Clin Endocrinol Metab 1999; 84: 3666-3672.

39 Keevil BG, Adaway J, Fiers $\mathrm{T}$, et al. The free androgen index is inaccurate in women when the SHBG concentration is low. Clin Endocrinol (Oxf) 2018; 88: 706-710.

40 Fry A, Littlejohns TJ, Sudlow C, et al. Comparison of sociodemographic and health-related characteristics of UK Biobank participants with those of the general population. Am J Epidemiol 2017; 186: 1026-1034. 